Original Article

\title{
Effects of task-oriented circuit training on balance and gait ability in subacute stroke patients: a randomized controlled trial
}

\author{
Kyoung Kim, PhD ${ }^{1)}$, SAng In Jung, MS, PT ${ }^{1)^{*}}$, Dong Kyu Lee, MS, PT ${ }^{1)}$ \\ 1) Department of Physical Therapy, College of Rehabilitation Science, Daegu University: 15 Jilyang, \\ Gyeongsan-si, Kyeongbuk 712-714, Republic of Korea
}

\begin{abstract}
Purpose] The aim of this study was to investigate the effects of the task-oriented circuit training on balance and gait ability in subacute patients with stroke. [Subjects and Methods] Participants were randomly allocated to two groups: group 1 (subjects who performed task-oriented circuit training) and group 2 (subjects who underwent conventional physical therapy). Berg balance scale, timed up and go test, functional ambulation category, 6-minute walk test were assessed before and after four weeks of training. [Results] There were significant differences between groups for the 6-minute walk test. [Conclusion] The result of this study showed that task-oriented circuit training could improve the gait ability in patients with subacute stroke.

Key words: Stroke, Task-oriented circuit training, Gait ability
\end{abstract}

(This article was submitted Jan. 16, 2017, and was accepted Mar. 11, 2017)

\section{INTRODUCTION}

Stroke is the second or third most common cause of death, one of the main causes of adult disability worldwide and is a global health problem ${ }^{1)}$. Although stroke rehabilitation improves walking competency, $50 \%$ to $65 \%$ of stroke patients are left with functional impairments ${ }^{2,3)}$. Most patients are still significantly disabled beyond 6 months after stroke, and do not return to social activities within the community ${ }^{4)}$.

Several methods can improve walking competency. Task-oriented practice performed at a high intensity may enhance walking competency in people with stroke ${ }^{5}$. Many randomized controlled trial studies ${ }^{5-7)}$, found circuit class training to be effective in improving walking ability and postural control with standing, in patients after chronic stroke. A recent metaanalysis suggested that circuit class therapy was safe improved mobility in people after stroke, and reduced the length of hospital stay ${ }^{8}$.

This study designed task-oriented circuit training program to improve balance and gait performance. The purpose of this study was to investigate the effects of the task-oriented circuit training on balance and gait ability in patients with subacute stroke.

\section{SUBJECTS AND METHODS}

Thirty subacute stroke patients were admitted as inpatients in the rehabilitation centres from South Korea. This was a randomized clinical trial. Randomization was performed by flipping a coin, and all subjects $(n=30)$ were assigned to either the task-oriented circuit training $(n=15)$ or conventional therapy $(n=15)$ group.

All subjects confirmed clinically by computed tomography scans or magnetic resonance imaging. Inclusion criteria were: patients were within 6 months after stroke; presented the ability to walk at least 10 meter alone or with an aid, but without

*Corresponding author. Sang In Jung (E-mail: normalman80@gmail.com)

(C2017 The Society of Physical Therapy Science. Published by IPEC Inc.

This is an open-access article distributed under the terms of the Creative Commons Attribution Non-Commercial No Derivatives (by-nc-nd) License $<$ https://creativecommons.org/licenses/by-nc-nd/4.0/>. 
Table 1. General characteristics for both groups

\begin{tabular}{lcc}
\hline Group & $\begin{array}{c}\text { Experimental group } \\
(\mathrm{n}=15)\end{array}$ & $\begin{array}{c}\text { Control group } \\
(\mathrm{n}=15)\end{array}$ \\
\hline Gender (Male/Female) & $10 / 5$ & $9 / 6$ \\
Side of stroke lesion (Left/Right) & $8 / 7$ & $10 / 5$ \\
Stroke type (Hemorrhage/Infarct) & $9 / 6$ & $8 / 7$ \\
Age (years) & $57.3(12.3)$ & $54.0(11.8)$ \\
Onset (months) & $3.3(1.3)$ & $4.4(1.6)$ \\
\hline
\end{tabular}

Values are showed as frequency or mean (standard deviation).

standby assistance. Exclusion criteria were: atrial fibrillation, uncontrolled hypertension, symptoms of unstable cardiac disease, recent pulmonary embolism, and subacute systemic illness or infection.

Informed consent was voluntarily obtained from all the subjects before participation in the study, and this study was approved by the institutional human ethics committees, and written informed consent was obtained from all subjects, before their participation.

Both the groups received neuro-developmental treatment (postural control exercise, resistance exercise, and functional activity exercise) for approximately 1 hour per day. In addition, they received some other therapies, including occupational and speech therapy, as needed.

Subjects in the intervention group participated in a task-oriented circuit training at the rehabilitation centre, for a total of 50 minutes, five times a week, for 4 weeks. The length of intervention was 4 weeks, 5 sessions of weekly training, for a total of 20 sessions. All training sessions were organized into groups, with at least 2-3 people/group, and were conducted by two physical therapists (with 3 years of experience in stroke rehabilitation).

Task-oriented circuit training program was modified according to the studies by Dean et al. ${ }^{6}$ and Outermans et al. ${ }^{9}$ and incorporated 10 workstations. It consisted of task-oriented activities for improving balance, walking competency, and respiration ability. At all stations patients practiced for 3 minutes, and this session was followed by a 1 minute transfer to the next station. And stretching time ( 5 minutes) was offered before and after the exercise. The total exercise time was 50 minutes.

These core practice activities were: sit to stand; stepping; tandem standing; one leg standing; and reaching; walking practice included obstacles, reaching, slope and stairs. These core activities were individually adjusted for each subject by the treating therapist. Progress was assessed as required, such that the level of difficulty, complexity, and dosage (number of repetitions) matched the ability of each individual ${ }^{10)}$. The Borg Scale of Perceived Exertion was used to adjust the effort intensity in order to maintain an "hard" level ${ }^{11)}$. Details about exercise intensity and/or repetitions performed at each station were recorded for each participant.

The control group was performed through exercise focused on task-oriented exercise, such as strengthening exercise (resistance exercise), standing balance (using varying methods), and functional activities for gait improvement.

To determine the subjects' balance and gait ability, we examined Berg Balance Scale (BBS), Timed up and Go Test (TUG), Functional Ambulation Category (FAC) and 6 minute Walk Test (6MWT).

In order to determine the walking ability and the level of endurance for FAC, the 6MWT was conducted with participants wearing shoes and using their usual assistive devices such as cane or ankle foot orthosis. FAC was calculated by according to the scores at their most independent level (supervision or physical assistance required to ambulate) ranging from 0 to 5 . The test is based on a walking distance of $15 \mathrm{~m}$ and is performed with a cane ${ }^{12}$. 6MWT is a clinically useful measure of walking ability post stroke. It incorporates the important requirements for ambulation, such as walking endurance, balance, and speed. It is performed at the fastest speed possible during walking, which is individually determined, making it ideal for stroke survivors. It measures the ability to walk for a maximum distance, within the 6 minute test duration.

Descriptive statistics was used in order to process the general characteristics of the participants. The independent $t$-test was used to compare the demographic data and the baseline characteristics of the two groups. The paired t-test was used to compare in-group data before and after the intervention. Pre- and post-test differences in balance and gait ability between the experimental group and the control group were compared using the independent t-test. The statistical significance level was set at 0.05 .

\section{RESULTS}

Thirty subjects were included in each group for a total of 30 subjects. General characteristics of subjects were not significantly different between the groups $(\mathrm{p}>0.05)$ in Table 1 . The observational data regarding BBS, TUG, FAC, 6-minute walking test of both groups is summarized in Table 2. Analysis of the effects for within-group changes over time revealed significant improvements for both groups on BBS, TUG, FAC, 6-minute walk test $(p<0.05)$. Significant difference was noted in the 6-minute walking test of the two groups $(\mathrm{p}<0.05)$ in Table 2. 
Table 2. Balance and walking ability values and variation after four weeks of intervention for both groups

\begin{tabular}{lcccccc}
\hline & \multicolumn{3}{c}{ Experimental group $(\mathrm{n}=15)$} & \multicolumn{3}{c}{ Control group $(\mathrm{n}=15)$} \\
\cline { 2 - 7 } & Pre-test & Post-test & Post-Pre test & Pre-test & Post-test & Post-Pre test \\
\hline BBS & $45.0(9.5)$ & $51.6(7.1)^{*}$ & $6.60(6.58)$ & $40.9(9.0)$ & $46.1(7.2)^{*}$ & $5.27(5.25)$ \\
TUG & $20.9(23.8)$ & $14.4(16.5)^{*}$ & $-6.55(8.76)$ & $27.2(20.8)$ & $20.7(14.8)^{*}$ & $-5.27(5.25)$ \\
FAC & $3.5(1.1)$ & $4.4(0.8)^{*}$ & $0.93(0.70)$ & $3.1(1.19)$ & $4.00(0.8)^{*}$ & $0.87(0.64)$ \\
6MWT (m) & $233.4(143.8)$ & $336.7(159.6)^{*}$ & $103.33(82.62)$ & $160.7(115.5)$ & $202.80(119.1)^{*}$ & $42.07(36.09)^{*}$ \\
\hline
\end{tabular}

Values are mean (standard deviation)

*Significant difference between pre-post test $\left({ }^{*} \mathrm{p}<0.05\right)$

BBS: berg balance scale; TUG: timed up and go test; FAC: functional ambulation category; 6MWT: 6-minute walk test

\section{DISCUSSION}

After analyzing the results of this study, we found that task-oriented circuit training improved gait endurance in subacute stroke patients. More importantly, values for the 6-minute walk test showed significant improvements in the experimental group, when compared to the control group. These changes represent the therapeutic effect of the task-oriented circuit training for patients after subacute stroke.

The largest effect between group treatments during the four week intervention was found for the 6-minute walk test. Our results are similar to the previous studies ${ }^{13)}$ reported that circuit training increased the 6-meter walk test results and also had a positive effect on the gait endurance in acute and chronic stroke patients. Walking ability, as measured with the 6-minute walk test is associated with a higher quality of life and is a good predictor for the walking capacity in these patients ${ }^{3)}$. Flansbjer et al. ${ }^{14)}$ suggested that improvement on the distance of the 6-minute walk test must exceed $13 \%$ in order to be clinically meaningful. Our findings revealed that both groups significantly improved. While the experimental group averaged a distance increase from $233.40 \mathrm{~m}$ to $336.73 \mathrm{~m}$ with a $44.27 \%$ increase, control group presented a $26.17 \%$ increase. Significant difference in between-groups was identified for the 6-minute walk test $(\mathrm{p}=0.01)$. This result might be due to adequate training as intensity and frequency, with the use of progressive increase in task-oriented circuit training program.

Although no significant difference in the variation of BBS, TUG, FAC were observed between experimental and control groups, BBS, TUG, FAC were significantly showed pre- and post-training within both groups. Therefore, task-oriented circuit training would benefit the balance and gait ability in subacute stroke patient.

There are several limitations to this study. First, the major limitation of this study was the lack of follow-up. We could not assess whether the subjects in the experimental group can maintain these changes. Therefore, we advised our patients to perform their task-oriented exercises regularly. Second, our study included relatively small number of subjects capable of independent 10 meter walk, not severity of stroke was measured. Therefore, our findings might not be generalized to all stroke patients. However, our study investigated the effect of the task-oriented circuit training on the pulmonary function.

Future studies should further extend this study in order to evaluate the missing insights. In particular, a comparison with other treatment methods for improvement in pulmonary function will be necessary.

These findings suggested that task-oriented circuit training could improve the gait ability in patients with stroke. Therefore, task-oriented circuit training should be considered as an essential part of the physical therapy program for subacute stroke patients. Furthermore, continuous further studies on task-oriented circuit training program and intervention are necessary in order to improve the gait ability and pulmonary function in patients with stroke.

\section{REFERENCES}

1) Bonita R, Mendis S, Truelsen T, et al.: The global stroke initiative. Lancet Neurol, 2004, 3: 391-393. [Medline] [CrossRef]

2) Duncan PW, Zorowitz R, Bates B, et al.: Management of adult stroke rehabilitation care: a clinical practice guideline. Stroke, 2005, 36: e100-e143. [Medline] [CrossRef]

3) Mudge S, Stott NS: Timed walking tests correlate with daily step activity in persons with stroke. Arch Phys Med Rehabil, 2009, 90: 296-301. [Medline] [CrossRef]

4) Perry J, Garrett M, Gronley JK, et al.: Classification of walking handicap in the stroke population. Stroke, 1995, 26: 982-989. [Medline] [CrossRef]

5) Salbach NM, Mayo NE, Wood-Dauphinee S, et al.: A task-orientated intervention enhances walking distance and speed in the first year post stroke: a randomized controlled trial. Clin Rehabil, 2004, 18: 509-519. [Medline] [CrossRef]

6) Dean CM, Richards CL, Malouin F: Task-related circuit training improves performance of locomotor tasks in chronic stroke: a randomized, controlled pilot trial. Arch Phys Med Rehabil, 2000, 81: 409-417. [Medline] [CrossRef]

7) Yang YR, Wang RY, Lin KH, et al.: Task-oriented progressive resistance strength training improves muscle strength and functional performance in individuals with stroke. Clin Rehabil, 2006, 20: 860-870. [Medline]

8) English C, Hillier S: Circuit class therapy for improving mobility after stroke: a systematic review. J Rehabil Med, 2011, 43: 565-571. [Medline] [CrossRef] 
9) Outermans JC, van Peppen RP, Wittink H, et al.: Effects of a high-intensity task-oriented training on gait performance early after stroke: a pilot study. Clin Rehabil, 2010, 24: 979-987. [Medline] [CrossRef]

10) English CK, Hillier SL, Stiller KR, et al.: Circuit class therapy versus individual physiotherapy sessions during inpatient stroke rehabilitation: a controlled trial. Arch Phys Med Rehabil, 2007, 88: 955-963. [Medline] [CrossRef]

11) Borg G: Ratings of perceived exertion and heart rates during short-term cycle exercise and their use in a new cycling strength test. Int J Sports Med, 1982, 3 : 153-158. [Medline] [CrossRef]

12) Holden MK, Gill KM, Magliozzi MR, et al.: Clinical gait assessment in the neurologically impaired. Reliability and meaningfulness. Phys Ther, 1984, 64: 35-40. [Medline] [CrossRef]

13) Blennerhassett J, Dite W: Additional task-related practice improves mobility and upper limb function early after stroke: a randomised controlled trial. Aust J Physiother, 2004, 50: 219-224. [Medline] [CrossRef]

14) Flansbjer UB, Holmbäck AM, Downham D, et al.: Reliability of gait performance tests in men and women with hemiparesis after stroke. J Rehabil Med, 2005, 37: 75-82. [Medline] [CrossRef] 